\title{
Comparison of Different Multilevel Voltage Source Inverter Topologies on Induction Motor Energy Quality
}

\author{
Abdelhalim Yahiaoui $^{1 *}$, Koussaila Iffouzar ${ }^{1,2}$, Kamal Himour $^{3}$, Kaci Ghedamsi $^{1}$ \\ ${ }^{1}$ Laboratoire de Maitrise des Energies Renouvelables, Faculté de Technologie, Université de Bejaia 06000, Bejaia, Algeria \\ ${ }^{2}$ Ecole supérieure des Sciences Appliquées d'Alger, Département Second Cycle, Alger 16000, Algerie \\ ${ }^{3}$ Département de Sciences et Technologies, Institut de Sciences, Centre Universitaire Nour Bachir, El Bayadh 32000, Algerie
}

Corresponding Author Email: yahiaouiabdelhalim@hotmail.fr

https://doi.org/10.18280/ejee.210404

Received: 11 February 2019

Accepted: 19 June 2019

\section{Keywords:}

Modular Multilevel Voltage Source

Inverter (MMVSI), Neutral Point

Clamped Voltage Source Inverter

(NPCVSI), Three-Phase Induction Motor

(3 IM), Phase Disposition Pulse Width

Modulation (PD-PWM)

\begin{abstract}
The modular multilevel converter (MMC) is a kind of converter commonly used for medium and high voltage applications, such as a high voltage direct current (HVDC) transmission, due to his modularity that allows reaching different voltage level. This paper reports a comparison study of a three-phase induction motor (3 IM) energy quality piloted by two different multilevel converters, the modular multilevel source voltage inverter (MMVSI) and the neutral point clamped source voltage inverter (NPCVSI). Indeed, the main purpose of this document is to show the interest of training the induction motor (3 IM) with the multilevel modular inverter (MMVSI), for this, we use a comparison with the (NPCVSI). For that, the two converters are controlled with a phase disposition pulse width modulation (PD-PWM) technique. Firstly, the mathematic models of the 3 IM, MMVSI and NPCVSI are given, then, control strategy for the two topologies and finally, the simulation analysis of the two systems has been done with MATLAB/SimPowerSystems and the different comparison aspects and results are shown and discussed.
\end{abstract}

\section{INTRODUCTION}

The modular multilevel converter (MMC) [1] becomes one of the most preferred converters for medium-voltage and highpower applications compared to the classical converters (Neutral point clamped, Stacked cell, etc....). Indeed, his modularity allows increasing easily the number of the output voltage's level, hence, reducing the voltage stress on power switches and permit to synthesis a voltage with low harmonic contents. This converter is often used in electric power transmission systems such as HVDC [2-4] and as a static synchronous compensator STATCOM [5]. Then, the neutral point clamped converter [6] is used in many areas such as grid connections, a static compensation and is most used in traction systems $[7,8]$.

Many works are done in motor drive based MMC $[9,10]$. However, the question asked here is, that the MMC topology ranks its advantage for a traction system. The present paper discusses a comparison of said topology with another topology that is often used in traction systems that is the NPC inverter. Indeed, the principal idea of this work is to compare driving of the three-phase induction motor with two different converter topologies, the first who's the NPC source voltage inverter topology that is a mature technology nowadays in this area, the second one is the MMC source voltage inverter topology who is more desirable, till now, for a high voltage transmission.

The remainder of this paper is organized as follows: Firstly, the mathematic models of the different parts are done. Then, we develop these models with MATLAB/SimPowerSystems, where the numeric simulations are done. Finally, we present a comparison study for the two systems based on simulation results and the components of each converter.

\section{SYSTEM MODELING}

\subsection{Modeling of the three-phase induction motor}

The three phase IM associated with power electronics converters are widely explored in the field of electrical energy conversion $[11,12]$. Eq. (1) follows the model of induction motor described in the natural frame:

$$
\left\{\begin{array}{l}
{\left[V_{s}\right]=\left[R_{S}\right]\left[I_{s}\right]+\frac{d}{d t}\left[\varphi_{s}\right]} \\
{\left[V_{r}\right]=\left[R_{r}\right]\left[I_{r}\right]+\frac{d}{d t}\left[\varphi_{r}\right]}
\end{array}\right.
$$

With applying the transition matrix to the rotating coordinate system, we obtain the following system:

$$
\left\{\begin{array}{c}
V_{d s}=R_{s} i_{d s}-\omega_{s} i_{q s}+\frac{d}{d t} \varphi_{d s} \\
V_{q s}=R_{s} i_{q s}+\omega_{s} i_{d s}+\frac{d}{d t} \varphi_{q s} \\
0=R_{r} i_{d r}-\omega_{r} i_{q r}+\frac{d}{d t} \varphi_{d r} \\
0=R_{r} i_{q r}+\omega_{r} i_{d r}+\frac{d}{d t} \varphi_{q r}
\end{array}\right.
$$

As, the flux equations are given by Eq. (3): 


$$
\left\{\begin{array}{l}
\varphi_{d s}=L_{s} \cdot i_{d s}+M . i_{d r} \\
\varphi_{q s}=L_{s} \cdot i_{q s}+M . i_{q r} \\
\varphi_{d s}=L_{r} \cdot i_{d r}+M . i_{d s} \\
\varphi_{q r}=L_{r} \cdot i_{q r}+M . i_{q s}
\end{array}\right.
$$

The equation of the electromagnetic torque and express by driving the expression of the co-energy of which it results the following equation:

$$
\Gamma_{e m}=p \frac{M}{L_{r}}\left(\varphi_{i q s}-\varphi_{q r}{ }^{i} d s\right)
$$

\subsection{Circuit configuration and mathematic model of a 5- level MMVSI}

The Figure 1 (a) shows a circuit representation of one leg of a five level MMVSI. It consists of two arms, where each arm includes four series-connected, identical, Sub Modules (SM's) and each sub module consist of a half bridge Figure 1 (b). Reactors $\mathrm{L}_{0}$ are to limit the fault currents and to provide current control (suppression of circulating current). The output voltage of each SM is either equal to its capacitor voltage (V) or zero, depending on the switching states of the switch pairs $S_{1}$ and $S_{2}$ in each SM (Table 1). Each sub module consists of a DC capacitor and two IGBTs with anti-parallel diodes that control the output voltage of a module to be capacitor voltage or zero.

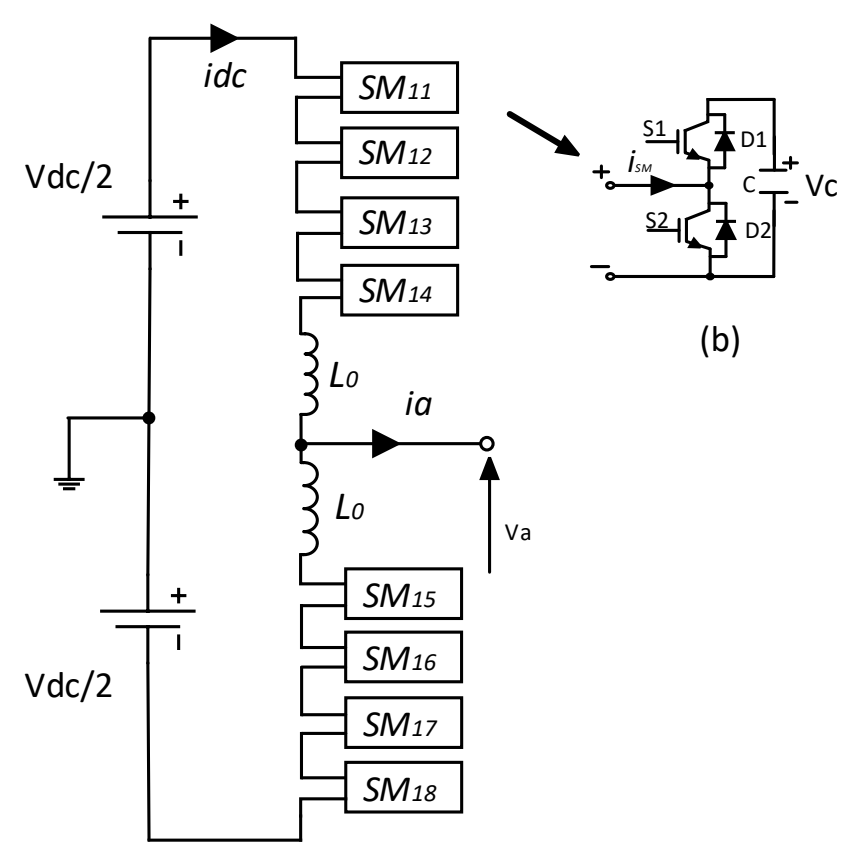

(a)

Figure 1. (a). Schematic representation one leg of a 5-level MMVSI, (b) Sub-module (SM)

Table 1. SM states and its output voltage

\begin{tabular}{ccccccc}
\hline S1 & S2 & D1 & D2 & Current & $\begin{array}{c}\text { Capacitor } \\
\text { state }\end{array}$ & $\begin{array}{c}\text { Output } \\
\text { voltage }\end{array}$ \\
\hline OFF & ON & OFF & OFF & $\mathrm{i}_{\text {arm }}>0$ & Uncharged & 0 \\
\hline OFF & OFF & OFF & ON & $\mathrm{i}_{\text {arm }}<0$ & Uncharged & 0 \\
\hline ON & OFF & ON & OFF & $\mathrm{i}_{\text {arm }}>0$ & Charge & Vc \\
\hline ON & OFF & OFF & OFF & $\mathrm{i}_{\text {arm }}<0$ & Discharging & Vc \\
\hline
\end{tabular}

In a three-phase inverter, each arm can be controlled with an insertion index $n(t)$, where $n(t)=0$ means that all submodules in the arm are by-passed, on the other side $n(t)=1$ means that all the sub-modules in the arm are inserted.

The instantaneous arm voltages can be represented by Eq. (5) and Eq. (6), where the capacitor voltages are kept balanced using a voltage-balancing algorithm [13]:

$$
\begin{gathered}
v_{c u}=n_{u}(t) \cdot \sum_{1}^{N} u_{c u} \\
v_{c l}=n_{l}(t) \cdot \sum_{1}^{N} u_{c l}
\end{gathered}
$$

$n_{u}(t)$ and $n_{l}(t)$ are the insertion indices for upper and lower arm, respectively. They are the number of sub module inserted to the way of current. They can be calculated from the modulation technique [13].

$$
\sum_{1}^{N} u_{c u} \text { and } \stackrel{N}{\sum} u_{c l} \text { represent, respectively, the total }
$$

capacitor voltage in the upper and lower arms and $\mathrm{N}$ represents the number of SM in each arm.

Eq. (7) and Eq. (8) show the mathematical relationship between the output current, circulating current and the arm current [14]:

$$
\begin{gathered}
i_{u, j}=\frac{i_{d c}}{3}+i_{c i r c}, j+\frac{i_{j}}{2} \\
i_{l, j}=\frac{i_{d c}}{3}+i_{c i r c, j}-\frac{i_{j}}{2}
\end{gathered}
$$

where, $i_{u}$, and $i_{1}$, are the upper and lower current of phase- $j$, respectively, and $i_{\text {circ }}$, represents the circulating current within phase- $j, i_{j}$ represents the ac-side current of phase- $j$ and $i_{d c}$ is the DC link current.

The dynamic behavior of the MMVSI phase- $\mathrm{j}$ is governed by Eq. (9) and Eq. (10)

$$
\begin{aligned}
& \frac{V d c}{2}-v_{p, j}=L_{0} \frac{d i p, j}{d t}+v_{j o} \\
& \frac{V d c}{2}-v_{n, j}=L_{0} \frac{d i_{n, j}}{d t}+v_{j o}
\end{aligned}
$$

where, $\mathrm{v}_{\mathrm{p}, \mathrm{j}}$, and $\mathrm{v}_{\mathrm{n}, \mathrm{j}}$, represent the upper and lower arm voltages, respectively, and vjo represents the output voltage of phase-j. The numerical value of Vjo is given by (11):

$$
v_{j o}=\frac{v_{n, j}-v_{p, j}}{2}-\frac{L_{0}}{2} \frac{d i j}{d t}
$$

Table 2 shows the switching states on one leg of a five level inverter and the output voltage level, where $\mathrm{M}$ and $\mathrm{L}$ represent the number of switches in ON state for upper and lower arm respectively. Va1, Va2 and $\mathrm{Va}$ represent a voltage level of upper and lower arm and the leg's output voltage level respectively. 
Table 2. 5-levels MMC inverter switching states and voltage levels

\begin{tabular}{ccccc}
\hline $\mathbf{M}$ & $\mathbf{L}$ & $\mathbf{u a 1}$ & $\mathbf{u a 2}$ & $\mathbf{u a}$ \\
\hline 2 & 2 & $2 \mathrm{Vc}$ & $2 \mathrm{Vc}$ & 0 \\
\hline 1 & 3 & $\mathrm{Vc}$ & $3 \mathrm{Vc}$ & $\mathrm{Vc}$ \\
\hline 0 & 4 & 0 & $4 \mathrm{Vc}$ & $2 \mathrm{Vc}$ \\
\hline 3 & 1 & $2 \mathrm{Vc}$ & $2 \mathrm{Vc}$ & $-\mathrm{Vc}$ \\
\hline 4 & 0 & $2 \mathrm{Vc}$ & 0 & $-2 \mathrm{Vc}$ \\
\hline
\end{tabular}

\subsection{Circuit configuration and mathematic model of a 5-} level NPCVSI

The Figure 2 represents one leg of five level neutral point clamped, it consists of eight switches that are called $\mathrm{B}_{\mathrm{kj}}$.

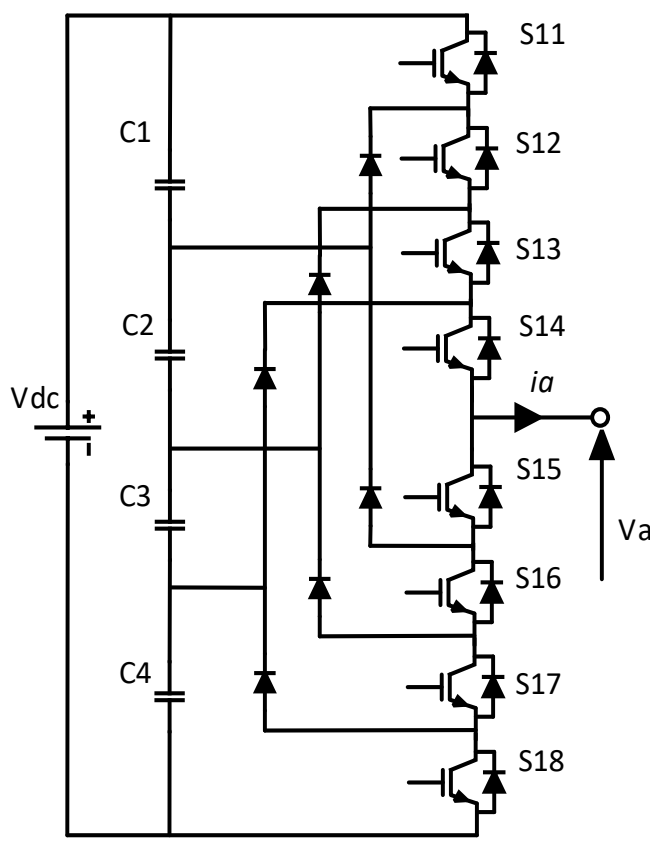

Figure 2. Schematic representation one leg of a 5-level NPCVSI

For each switch, $S_{i j} \quad(i=\overline{1-8}, j=\overline{1-3})$ we define a commutation function as:

$$
F_{i j}= \begin{cases}1 & \text { When } S_{i j} \text { is opened } \\ 0 & \text { When } S_{i j} \text { is opened }\end{cases}
$$

The optimal control low of a five level inverter is, [7]:

$$
F_{i j}=1-F(i-4) \quad(i=\overline{5-8}, j=\overline{1-3})
$$

Each leg of the inverter is associated with five-connection functions (Eq. 13), who are associated to the states of the leg (Table 3):

$$
\left\{\begin{array}{l}
F_{c 1 j}=F_{1 j} \cdot F_{2 j} \cdot F_{3 j} \cdot F_{4 j} \\
F_{c 2 j}=F_{2 j} \cdot F_{3 j} \cdot F_{4 j} \cdot F_{5 j} \\
F_{c 3 j}=F_{3 j} \cdot F_{4 j} \cdot F_{5 j} \cdot F_{6 j} \\
F_{c 4 j}=F_{4 j} \cdot F_{5 j} \cdot F_{6 j} \cdot F_{7 j} \\
F_{c 5 j}=F_{5 j} \cdot F_{6 j} \cdot F_{7 j} \cdot F 8 j
\end{array}\right.
$$

Table 3. Five level neutral point inverter switching states and voltage levels

\begin{tabular}{ccccccccc}
\hline $\mathbf{S}_{\mathbf{k} 1}$ & $\mathbf{S}_{\mathbf{k} 2}$ & $\mathbf{S}_{\mathbf{k} 3}$ & $\mathbf{S}_{\mathbf{k} 4}$ & $\mathbf{S}_{\mathbf{k} \mathbf{5}}$ & $\mathbf{S}_{\mathbf{k} 6}$ & $\mathbf{S}_{\mathbf{k} 7}$ & $\mathbf{S}_{\mathbf{k} 8}$ & $\mathbf{V}_{\mathbf{k}}$ \\
\hline 1 & 1 & 1 & 1 & 0 & 0 & 0 & 0 & $\mathrm{Vdc} / 2$ \\
\hline 0 & 1 & 1 & 1 & 1 & 0 & 0 & 0 & $\mathrm{Vdc} / 4$ \\
\hline 0 & 0 & 1 & 1 & 1 & 1 & 0 & 0 & 0 \\
\hline 0 & 0 & 0 & 1 & 1 & 1 & 1 & 0 & $-\mathrm{Vdc} / 4$ \\
\hline 0 & 0 & 0 & 0 & 1 & 1 & 1 & 1 & $-\mathrm{Vdc} / 2$
\end{tabular}

The output voltage is given by Eq. (14)

$$
\left(\begin{array}{l}
V_{a} \\
V_{b} \\
V_{c}
\end{array}\right)=\left(\begin{array}{lll}
2 & -1 & -1 \\
-1 & 2 & -1 \\
-1 & -1 & 2
\end{array}\right) \cdot\left(\begin{array}{l}
2\left(B_{11}-B_{12}\right)+\left(B_{17}-B_{18}\right) \\
2\left(B_{21}-B_{22}\right)+\left(B_{27}-B_{28}\right) \\
2\left(B_{31}-B_{32}\right)+\left(B_{37}-B_{38}\right)
\end{array}\right) \cdot \frac{V_{d c}}{2}
$$

\section{PHASE DISPOSITION PULSE WIDTH MODULATION (PD-PWM)}

Several modulation techniques are used for multilevel converter, based in high and fundamental frequency, in high frequency there are the PWM techniques (Phase shifted, Level shifted, Phase disposition and Phase opposite disposition) and in fundamental frequency, the most known modulation techniques are nearest level control (NLC) and the selective harmonic elimination (SHE). In this work, a carrier based Phase Disposition Pulse Width Modulation (PD-PWM) is used to control the two inverters, for a five level inverter four triangular carriers with the same frequency and amplitude so that they occupy a contiguous band over the range +0.5 . $\mathrm{V}_{\mathrm{dc}}$ to -0.5. $V_{\mathrm{dc}}$. A reference waveform for each phase is then compared against the carriers to determine how the phase leg should be switched (Figure 3).

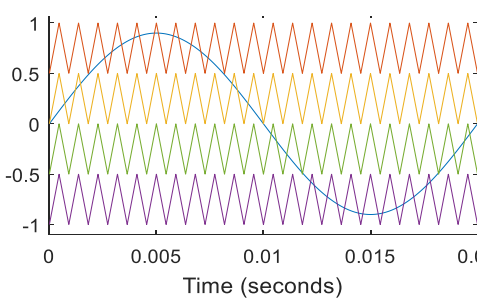

Figure 3. Phase Disposition PWM $\left(\mathrm{m}=0.9, \mathrm{f}_{\mathrm{c}}=1100 \mathrm{~Hz}\right)$

If the reference is greater than a carrier signal, then the active device corresponding to that carrier is switched $\mathrm{ON}$, and if the reference is less than the carrier signal, then the active device corresponding to that carrier is switched OFF.

\section{SIMULATION RESULTS AND INTERPRETATION}

The results presented in this section are obtained from a five-level modular and neutral point clamped multilevel inverter fed a three-phase induction motor in Matlab/SimPowerSystem, the phase disposition pulse width modulation (PD-PWM) is used to control the switching devices of both inverters. The switching frequency of the carriers is $1100 \mathrm{~Hz}$. The simulation parameters of the induction motor used in this work are carried in appendix. The torque load varies as follow: 
At $\mathrm{t}=0.8 \mathrm{~s}$ vary from 0 to 31.83 N.m (The nominal value);

At $\mathrm{t}=1.5 \mathrm{~s}$ vary from 31.83 to 0 N.m;

At $\mathrm{t}=2.2 \mathrm{~s}$ vary from 0 to -31.83 N.m;

At $\mathrm{t}=3 \mathrm{~s} \quad$ vary from -31.83 to 0 N.m.

Figures 4 and 5 show the electromagnetic torque and its zoom, we can see that is identical for both converter, figures 6 and 7 show the stator current and its zoom, then figures 8 and 9 present the harmonic analysis of the stator current. Figures 10 and 11 show the line-to-line voltage and his harmonic analysis for the NPCVSI and, finally, figures 13 and 14 show the line-to-line voltage and his harmonic analysis for the MMVSI. From this figure, we can see that the simulation results are nearly identical in both systems. All the simulation results are synthesized in Table 4.

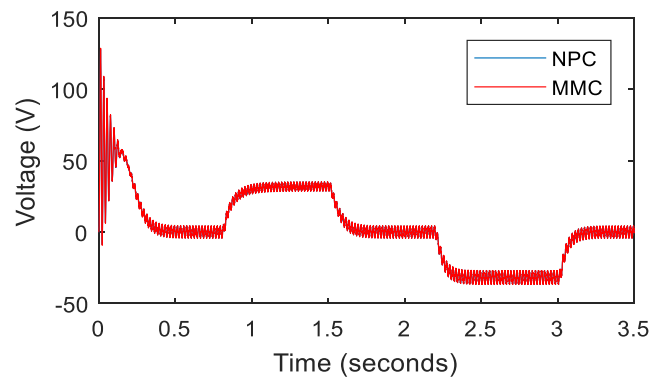

Figure 4. Electromagnetic torque

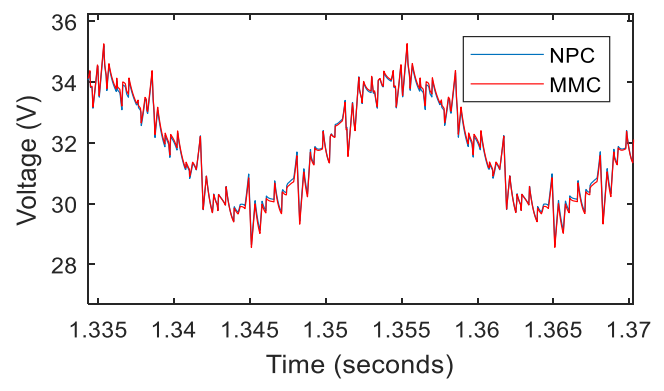

Figure 5. Electromagnetic torque's zoom

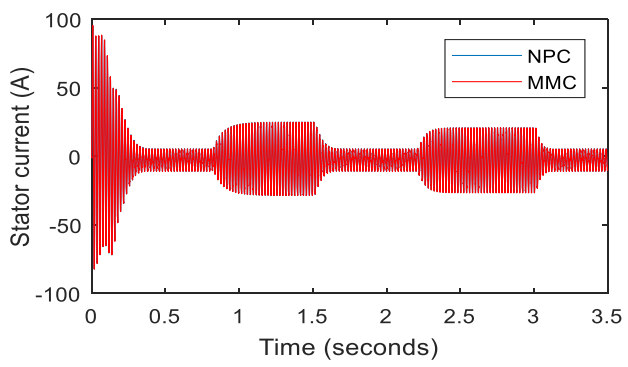

Figure 6. Stator current with NPCVSI and MMVSI

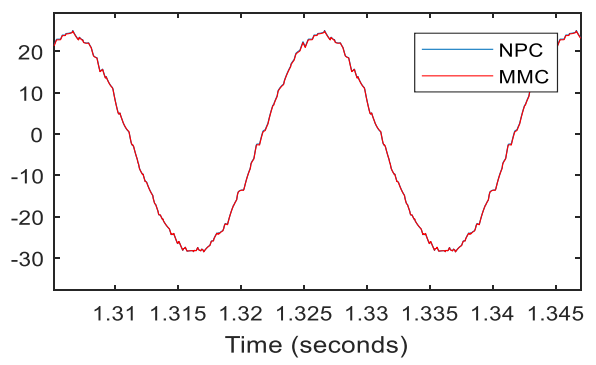

Figure 7. Zoom of stator currents with NPCVSI and MMVSI

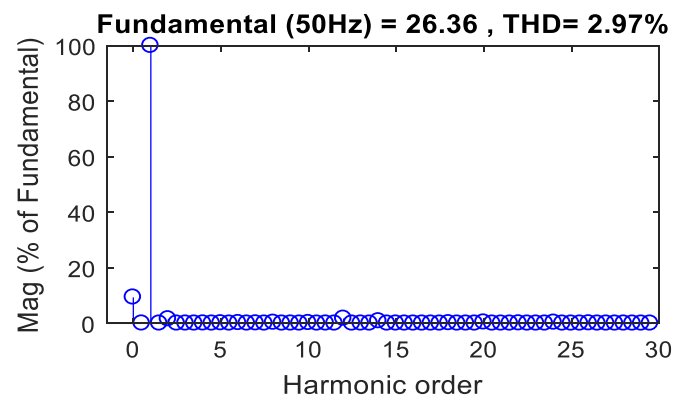

Figure 8. Stator current harmonic analysis of NPCVSI

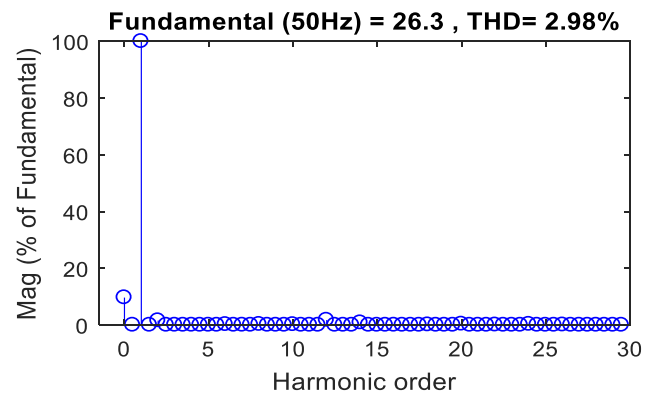

Figure 9. Stator current harmonic analysis of MMVSI

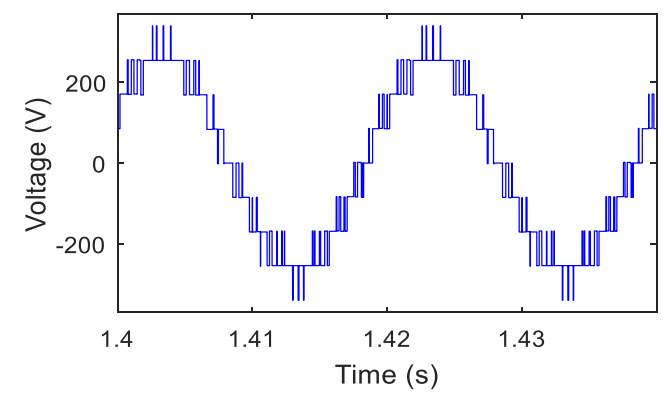

Figure 10. Stator line-to-line voltage for NPCVSI

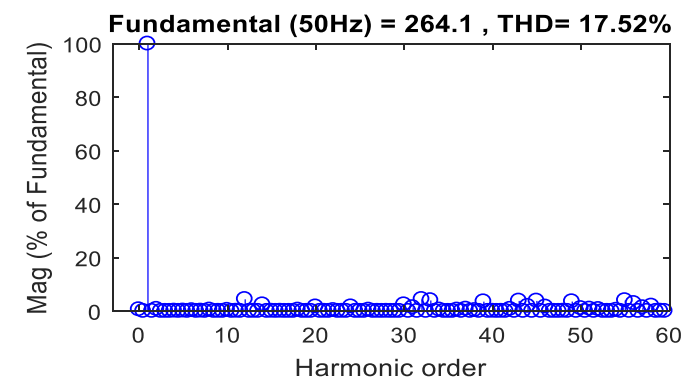

Figure 11. Harmonic analysis Stator line-to-line voltage for NPCVSI

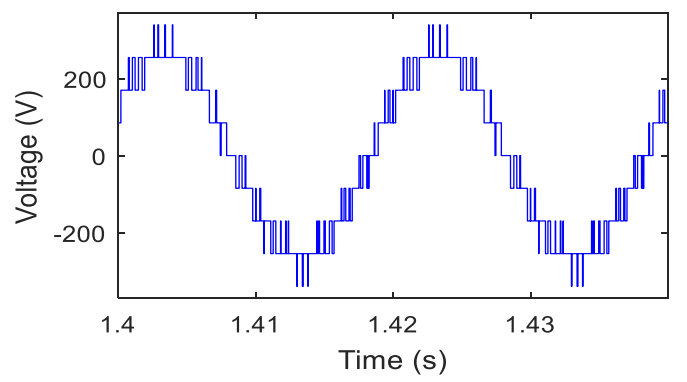

Figure 12. Stator line-to-line voltage for MMVSI 


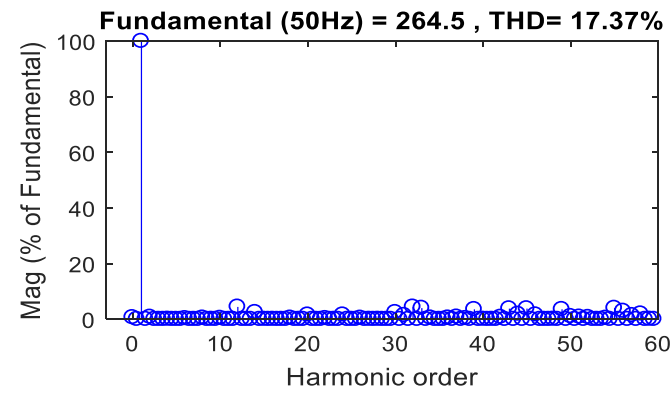

Figure 13. Harmonic analysis Stator line-to-line voltage for MMVSI

Table 4. MMVSI-5L and NPCVSI-5L Comparison

\begin{tabular}{ccc}
\hline & MMVSI-5 L & NPCVSI -5 L \\
\hline $\begin{array}{c}\text { Voltage fundamental } \\
\text { amplitude (V) }\end{array}$ & 264.5 & 264.1 \\
\hline Voltage THD \% & 17.37 & 17.52 \\
\hline $\begin{array}{c}\text { Current fundamental } \\
\text { amplitude (A) }\end{array}$ & 26.3 & 26.36 \\
\hline Current THD \% & 2.98 & 2.97 \\
\hline Number of power switches & $\mathbf{4 8}$ & $\mathbf{2 4}$ \\
\hline
\end{tabular}

\section{CONCLUSIONS}

In this paper, a five-level modular multilevel source voltage inverter (MMSVI) is used to drive an induction motor. Indeed, this converter is compared to a classical neutral point clamped source voltage inverter (NPCSVI), where the two multilevel inverters topologies are used to drive the induction motor and numeric simulations are carried in Matlab/SimPowerSystem, the both inverters are piloted by a Phase Disposition Pulse width modulation (PD-PWM). The results obtain are the same for both topologies. Nevertheless, the modular multilevel inverter presents some disadvantages, as the high number of switches required compared to the neutral point clamped inverter for the same level of output voltage (Table 4). Indeed, for twice the number of power switches we got the same results, and an additional control of voltage balancing of SM's capacitor is required. Hence, the modular multilevel converter is not recommended in case of motor drive compared to the neutral point clamped. By increasing the number of power switches, the failure rate increases, which reduces the reliability of MMC in traction systems and despite the quality of energy provided by this latter. Another study of the cost may seem interesting in this sense. However, the modular multilevel converter is highly desirable for medium and high voltage applications for the reasons mentioned above.

\section{REFERENCES}

[1] Lesnicar, A., Marquardt, R. (2003). An innovative modular multilevel converter topology suitable for a wide power range. In: Proceeding of Power Technology Conference, IEEE, Bologna Italy, pp. 23-26. http://dx.doi.org/10.1109/PTC.2003.1304403

[2] Teeuwsen, S.P. (2011). Modeling the trans bay cable project as voltage-sourced converter with modular multilevel converter design. IEEE Power and Energy Society General Meeting, Renaissance Center in Detroit,

Michigan,

USA.

http://dx.doi.org/10.1109/PES.2011.6038903

[3] Bergna Diaz, G. (2015). Modular multilevel converter control for HVDC operation. Ecole Doctorale STITS, Norwegian University of Science and Technology, Norway.

[4] Serbia, N. (2014). Modular multilevel converters for HVDC power stations. PhD, University of Toulouse, France.

[5] Pereira, M., Retzmann, D., Lottes, J., Wiesinger, M., Wong, G. (2011). SVC PLUS: An MMC STATCOM for network and grid access applications. In: Proceeding of the Power Tech, IEEE Trondheim, Norway.

[6] Nabae, A., Takahashi, I., Akagi, H. (1981). A new neutral-point-clamped PWM inverter. IEEE Transactions on Industry Applications, IA-17(5): 518523. http://dx.doi.org/10.1109/TIA.1981.4503992

[7] Himour, K. (2015). Optimisation des Systèmes Photovoltaïques par l'Insertion des Onduleurs Multiniveaux. PhD thesis, University of Bejaia, Algeria.

[8] Liu, X.H., Lin, X.C., Kang, Y., Lee, K. (2009). Simulation analysis of a three-level NPC based STATCOM combined with TSC on a wind farm. In: Proceedings of Energy Conversion Congress and Exposition, IEEE. San Jose, CA, USA, pp 378-381. http://dx.doi.org/10.1109/ECCE.2009.5316454

[9] Ekern, B.L. (2015). Modular multilevel converter for electric motor drive applications. Master of Energy and Environmental Engineering. Norwegian University of Science and Technology, Norway.

[10] Li, Y., Fan, L.L. (2015). Modular multilevel converter based induction machine drive. In: North American Power Symposium (NAPS), IEEE. Charlotte, NC, USA.

[11] Van Der Broeck, H.W., Van Wyk, J.D. (1984). A comparative investigation of a three-phase induction machine drive with a component minimized voltage fed inverter under different control options. IEEE Transactions on Industry Applications, IA-20(2): 309320. http://dx.doi.org/10.1109/TIA.1984.4504413

[12] Ion, B., Syed, A.N. (2010). The Induction Machines Design Handbook, Second Edition. Taylor \& Francis Group, USA.

[13] Ängquist, L., Antonopoulos, A., Siemaszko, D., Ilves, K., Vasiladiotis, M., Nee, H.P. (2010). Inner control of modular multilevel converters - an approach using openloop estimation of stored energy. International Power Electronics Conference (IPEC), Sapporo, Japan, pp. $1579-1585$ http://dx.doi.org/10.1109/IPEC.2010.5544607

[14] Siemaszko, D. (2015). Fast sorting method for balancing capacitor voltages in modular multilevel converters. IEEE Transactions on Power Electronics, 30(1): 463-470. http://dx.doi.org/10.1109/TPEL.2014.2312101

\section{NOMENCLATURE}

$\begin{array}{ll}\mathrm{dc} & \text { Direct current } \\ \mathrm{F} & \text { Friction factor } \\ \mathrm{IM} & \text { Induction motor } \\ \mathrm{HVDC} & \text { High Voltage Direct Current } \\ \mathrm{J} & \text { Moment of inertia } \\ \mathrm{L} & \text { Leakage inductance } \\ \mathrm{M} & \text { Mutual inductance }\end{array}$


MMC Modular Multilevel Converter

MMVSI Modular Multilevel Voltage Sourse Inverter

$\mathrm{N} \quad$ Number of SM in arm

NLC Nearest Level Control

NPC Neutral Point Clamped

NPCVSI Neutral Point Clamped Voltage Source Inverter

$\mathrm{p} \quad$ Number of pole pairs

PDPWM Phase Disposition Pulse Width Modulation

$\mathrm{S}$

SHE

$\mathrm{V}$

Power switch

Selective Harmonic Elimination

Voltage

\section{Greek symbols}

$\Gamma$

Torque N.m

$\varphi$
Mechanical speed $\mathrm{rad} / \mathrm{s}$

\section{Subscripts}

nf

$\mathrm{s}$

$\mathrm{r}$

d

q

em

$\mathrm{dc}$

ac

$\mathrm{u}$

1

circ fluid (pure water)

Nanofluid

Stator

Rotor

Direct axis

Quadratic axis

Electromagnetic

Direct current side

Alternative current side

Upper arm

Lower arm

Circulating current 